\title{
Exposure to airborne asbestos in thermal power plants in Mongolia
}

\author{
Naransukh Damiran ${ }^{1}$, Ellen K Silbergeld ${ }^{2}$, Arthur L. Frank ${ }^{3}$, \\ Oyuntogos Lkhasuren ${ }^{4}$, Chimedsuren Ochir ${ }^{1}$, Patrick N. Breysse ${ }^{2}$
}

\begin{abstract}
${ }^{1}$ School of Public Health, Mongolian National University of Medical Sciences, Ulaanbaatar, Mongolia, ${ }^{2}$ Johns Hopkins Bloomberg School of Public Health, Department of Environmental Health Sciences, ${ }^{3}$ Drexel University School of Public Health, ${ }^{4}$ World Health Organization
\end{abstract}

\begin{abstract}
Background: Coal-fired thermal power plants (TPPs) in Mongolia use various types of asbestos-containing materials (ACMs) in thermal insulation of piping systems, furnaces, and other products.

Objective: To investigate the occupational exposure of insulation workers to airborne asbestos in Mongolian power plants.

Methods: Forty-seven air samples were collected from four power plants in Mongolia during the progress of insulation work. The samples were analyzed by phase contrast microscopy (PCM) and transmission electron microscopy (TEM).

Results: The average phase contrast microscopy equivalent (PCME) asbestos fiber concentration was $0.93 \mathrm{f} / \mathrm{cm}^{3}$. Sixteen of the 41 personal and one of the area samples exceeded the United States Occupational Safety and Health Administration (US OSHA) short-term exposure limit of $1.0 \mathrm{f} / \mathrm{cm}^{3}$. If it is assumed that the short-term samples collected are representative of full-shift exposure, then the exposures are approximately 10 times higher than the US OSHA 8-hour permissible exposure limit of $0.1 \mathrm{f} / \mathrm{cm}^{3}$.

Conclusion: Power plant insulation workers are exposed to airborne asbestos at concentrations that exceed the US OSHA Permissible Exposure Limit. Action to mitigate the risks should be taken in Mongolia.
\end{abstract}

Keywords: Asbestos exposure, Mongolia, Thermal power plants, Chrysotile asbestos, Insulation

\section{Introduction}

Studies in developed countries have documented asbestos exposures in a variety of manufacturing and industrial settings, including insulation workers. ${ }^{1-5}$ Although asbestos use in most developed and some developing countries has been reduced or eliminated, it is still widely used in some developing countries where occupational regulations are limited or nonexistent. Few studies, however, have assessed asbestos exposures in low- and middle-income countries (LMICs). In 2007, Kangur studied asbestos exposure at Estonian oil shale-fueled power plants during plant renovations. Area airborne fiber concentrations released during renovation averaged $0.043 \pm 0.022 \mathrm{f} / \mathrm{cm}^{3}{ }^{6}$ In 2010 , Bhagia et al. documented thermal insulation board manufacturing workers in India that were exposed to asbestos at a concentration above the American Conference of Industrial Hygienists' (ACGIH) threshold limit value (TLV) of $0.1 \mathrm{f} / \mathrm{cm}^{3} .^{7}$ Recently, Cely-García et al. assessed worker exposure during car and truck brake

Correspondence to: Naransukh Damiran, School of Public Health, Mongolian National University of Medical Sciences, S. Zorig Street, Ulaanbaatar 14210, Mongolia. Email: naransukh.d@mnums.edu.mn maintenance activities in Bogota, Colombia. ${ }^{89}$ They found that asbestos brake processes (grinding, riveting, and cutting of friction products) that have been discontinued in developed countries are still common in Colombia. Chrysotile asbestos exposures during brake manipulation were in excess of safety and health standards. Also, in 2010, Felten et al. studied exposure to asbestos among the four main groups of workers employed in the power industry in Germany. All the groups, including the power generation and distribution workers in the industry, were occupationally exposed to asbestos. ${ }^{10}$

Coal-fired power plants in Mongolia commonly use asbestos-containing products, including powder, textiles, cords, boards, and sheets as thermal insulation material for piping systems, furnaces, and other installations. Insulation workers in coal-fired power plants are primarily exposed to asbestos during the maintenance and repair of the thermal insulation of piping systems and furnaces. ${ }^{11,12}$ Thermal insulation work at the thermal power plants (TPPs) in Mongolia consists of four main tasks: (1) removal of old thermal insulation from piping systems or furnaces; (2) disposal of asbestos-containing waste 
and insulation materials; (3) preparation of asbestos mixtures or other asbestos-containing materials (ACMs), including textiles, cords, and boards; and (4) installation of thermal insulation on pipes or furnaces. $^{12}$ Owing to the disruption of asbestoscontaining insulation materials, the insulation work releases asbestos-containing dust into the workplace. ${ }^{13}$

All the three coal-fired TPPs in Ulaanbaatar city (UB) and one of the two coal-fired TPPs in Erdenet city (Er) were selected for exposure assessment. The TPPs use ACMs to make thermal insulation for piping systems and furnaces. Insulation workers routinely remove, repair, and maintain thermal insulation materials as part of TPP maintenance activities. The magnitude of asbestos exposure during these activities is currently unknown. Based on our observation, safety precautions are rudimentary at the workplaces. Materials are not handled wet, containment areas are not established, and protective clothing, respirators, air conditioning, or technical ventilation - with or without filtering - are not used.

Current levels of exposure to asbestos in TPPs located in LMICs have not been reported in the literature. The purpose of this paper is to present the results of an asbestos exposure study conducted at four coal-fired TPPs in Mongolia, in UB, and in Er.

In Mongolia, there is at present little appreciation of the hazards of asbestos, including those from chrysotile. These health hazards have been noted by the International Agency for Research on Cancer (IARC), The Collegium Ramazzini, the United States Occupational Safety and Health Administration (US OSHA), and others. ${ }^{14-18}$ In the past, materials received from Russia or China carried no warnings. Five types of asbestos and ACMs have been banned in Mongolia since 2011; however, power plants have been exempted from this policy, and they continue to use asbestos extensively. Currently, there are no standards for occupational or general asbestos exposure in Mongolia.

\section{Materials and Methods}

Airborne asbestos exposure assessment was performed at four coal-fired power plants and 47 air samples (41 personal and 6 area samples) were collected (Table 1). Samples were collected and analyzed according to National Institute for Occupational Safety and Health (NIOSH) 7400 and 7402 methods, which included using mixed cellulose ester (MCE) membrane filters of $0.8 \mu \mathrm{m}$ pore size and $25 \mathrm{~mm}$ diameter, preloaded on electrically conductive extended cut cowl cassettes. ${ }^{19,20}$ For personal samples, battery operated portable air pumps (Air Check 224-XR series, SKC Inc., 863 Valley View Road Eighty Four, PA, USA) were used with the flow rate of $2.5 \mathrm{l} /$ min. The air sampling cassette was placed on the right shoulder in the worker's breathing zone. Because the work tasks released large amounts of dust, samples were collected for 12-81 minutes to avoid overloading the filters caused by non-asbestos dust. All personal air samples were collected from workers when they were performing thermal insulation work tasks as typically undertaken. Area samples were collected using either SKC Flite-2 pumps (operated at $5.61 /$ minute for 1517 minutes) or SKC Air Check 224-XR pumps (at 2.51 / minute for 18-24 minutes); the samples were collected at $1.5 \mathrm{~m}$ above the ground, and at 3, 4 and $20 \mathrm{~m}$ from the insulation worksites. Before and after the sampling, the air flow rates of all the air sampling pumps were measured with Defender 510 Medium BIOS International calibrators (Mesa Labs, Inc., 10 Park Place, Butler, NJ, USA). For quality control purposes, unused filters were included as blank samples (amounting to $10 \%$ of the total number of test samples analyzed).

The samples were analyzed by an American Industrial Hygiene Association (AIHA)-accredited laboratory: Forensic Analytical Laboratory, Hayward, CA, USA. Phase contrast microscopy (PCM) analysis was performed for all field and blank samples using the NIOSH 7400 method to determine the concentration of airborne fibers. After the PCM analysis, the 13 samples with the highest fiber concentrations were selected for

Table 1 Characteristics of air samples from Mongolian power plants $(n=4)$

\begin{tabular}{llcll}
\hline Power plants & Average sample time (minutes) $^{\text {aa }}$ & ${\text { Average sample volume, liters }\left(\mathbf{I}^{\text {aa }}\right.}$ & Job tasks involving asbestos \\
\hline$\# 1$ & PS $(n=22)$ & $37(23)$ & $89(56)$ & $\mathrm{A}, \mathrm{B}, \mathrm{C}^{\mathrm{a}}$ \\
& AS $(n=1)$ & 18 & 43 & $\mathrm{~B}$ \\
$\# 2$ & PS $(n=8)$ & $20(10)$ & $50(25)$ & $\mathrm{A}, \mathrm{B}, \mathrm{C}^{\mathrm{b}}, \mathrm{D}$ \\
& AS $(n=2)$ & $16(1)$ & $90(8)$ & $\mathrm{D}, \mathrm{E}$ \\
$\# 3$ & PS $(n=4)$ & $22(7)$ & $62(18)$ & $\mathrm{B}, \mathrm{C}^{\mathrm{b}}$ \\
& AS $(n=1)$ & 15 & 37 & $\mathrm{~B}^{\mathrm{b}}$ \\
$\# 4$ & PS $(n=7)$ & $19(7)$ & $48(18)$ & $\mathrm{A}$ \\
& AS $(n=2)$ & $18(8)$ & $45(21)$ & $\mathrm{A}$ \\
& Average $(n=47)$ & $28(19)$ & $71(45)$ & \\
\hline
\end{tabular}

AS: area samples; A: removing old insulation; B: preparing asbestos mixtures for insulation; $C^{\text {a }}$ installing insulation using mixtures of powder asbestos and asbestos-containing cord; $C^{b}$ : installing insulation using mixtures of powder asbestos; $\mathrm{D}$ : disposing of waste from old insulation materials; E: pipe welding; n: number of samples; PS: personal samples.

${ }^{\text {aa }}$ Standard deviation is shown in parentheses. 
transmission electron microscopy (TEM) analysis by the NIOSH 7402 method. The TEM provided a determination of asbestos in the workplace, and the percentage of asbestos within the total fibers of the samples. Based on the percentage of asbestos fibers found, phase contrast microscopy equivalent (PCME) asbestos fiber concentrations were calculated for all PCM samples. Transmission electron microscopy analyses were grouped according to power plant and the percentages of asbestos fibers were calculated using plant-specific percentage asbestos fiber correction factors.

All samples were collected by a single study team member (ND). Job tasks and work practices were observed during sampling events. Although samples were collected only over a short period, the workers typically (during the summer) worked with asbestos for a full work shift.

The researcher (ND) wore disposable protective coveralls (Tyvek, DuPont de Nemours, 4417 Lancaster Pike Wilmington, DE, USA) and a powered air-purifying respirator with a high-efficiency particulate air (HEPA) filter (Versaflo, 3M Corporate Headquarters, St. Paul, MN, USA) during the air sampling procedure. After the sampling, all contaminated equipment was thoroughly wetted and cleaned using a vacuum cleaner.

\section{Results}

The PCM results are summarized in Table 2. Fortysix of the 47 PCM samples were above the limit of detection (LOD $-0.05 \mathrm{f} / \mathrm{cm}^{3}$ ). The overall average PCM fiber concentration in the workplace was 0.96 $\mathrm{f} / \mathrm{cm}^{3}$, with a range of $<0.05$ to $3.15 \mathrm{f} / \mathrm{cm}^{3}$. The average personal airborne fiber concentration was $1.03 \pm 0.68 \mathrm{f} /$ $\mathrm{cm}^{3}$, with a range of $0.09-3.15 \mathrm{f} / \mathrm{cm}^{3}$. Area samples were lower, with a mean of $0.49 \pm 0.51 \mathrm{f} / \mathrm{cm}^{3}$ (range of $\left.<0.05-1.48 \mathrm{f} / \mathrm{cm}^{3}\right)$.

The TEM results are shown in Table 3. NIOSH method 7402 provides an estimate of the fraction of the optically visible fibers that are of asbestos. The TEM results indicated that most of the fibers counted were of asbestos, with an overall fraction equal to 0.97 (range $0.91-1.0$ ). For power plants 1, 3, and 4, all the fibers observed were of chrysotile. For power plant 2, both chrysotile and tremolite were observed.

As a result of the high asbestos fiber fraction noted in Table 3, the PCME results are similar to the unadjusted PCM fiber counts (Table 2). The average PCME was $0.93 \pm 0.70 \mathrm{f} / \mathrm{cm}^{3}$, slightly lower than the PCM concentration.

Sixteen of the 41 personal and one of the area samples exceeded the US OSHA short-term (30 minutes) exposure limit of $1.0 \mathrm{f} / \mathrm{cm}^{3} .{ }^{21}$ If we assume that the short-term samples collected are representative of the full-shift exposure, then the exposures are approximately 10 times higher than the US OSHA 8-hour permissible exposure limit of $0.1 \mathrm{f} / \mathrm{cm}^{3}$. The US OSHA standard is referenced here because Mongolia does not currently have an occupational exposure standard for asbestos.

Analysis of the fiber concentrations by work task indicated that disposing of old thermal insulation material generated the largest amount of fibers (mean PCM concentration of $1.34 \pm 0.98 \mathrm{f} / \mathrm{cm}^{3}$ ), while

Table 2 Airborne fiber concentrations at thermal insulation workplaces in the four Mongolian power plants

\begin{tabular}{|c|c|c|c|c|c|}
\hline Power plants & Type of sample & Job task & $N$ & $\begin{array}{l}\text { Average PCM } \\
\text { concentration, } \\
\text { fiber } / \mathrm{cm}^{3} \text { aa }\end{array}$ & $\begin{array}{l}\text { Average PCME } \\
\text { concentration, } \\
\text { fiber } / \mathrm{cm}^{3} \text { aa }\end{array}$ \\
\hline \multirow[t]{6}{*}{$\# 1$} & PS & A & 3 & 1.16 & 1.15 \\
\hline & & B & 6 & 0.62 & 0.60 \\
\hline & & $\mathrm{C}^{\mathrm{a}}$ & 7 & 1.03 & 1.01 \\
\hline & & $\mathrm{F}$ & 1 & 0.73 & 0.67 \\
\hline & & $\mathrm{D}$ & 5 & 1.18 & 1.14 \\
\hline & AS & At $3 \mathrm{~m}$ from asbestos mixture preparation site & 1 & 1.48 & 1.48 \\
\hline \multirow[t]{5}{*}{ \#2 } & PS & $\mathrm{D}$ & 2 & 1.76 & 1.63 \\
\hline & & $\mathrm{C}^{\mathrm{C}}$ & 1 & 1.68 & 1.63 \\
\hline & & A & 3 & 1.14 & 1.12 \\
\hline & & $\mathrm{B}$ & 2 & 0.89 & 0.85 \\
\hline & AS & At 4 and $20 \mathrm{~m}$ from insulation worksite & 2 & 0.39 & 0.39 \\
\hline \multirow[t]{3}{*}{ \#3 } & PS & $\mathrm{B}$ & 3 & 1.70 & 1.70 \\
\hline & & $C^{b}$ & 1 & 0.09 & 0.09 \\
\hline & AS & At 3 m from insulation installation site (outside) & 1 & $<0.04^{* *}$ & $<0.04^{* *}$ \\
\hline \multirow[t]{2}{*}{ \#4 } & PS & A & 7 & 0.77 & $0.74^{*}$ \\
\hline & AS & $A$ & 2 & 0.32 & $0.31 *$ \\
\hline Average & & & 47 & $0.96(0.68)$ & $0.93(0.70)$ \\
\hline
\end{tabular}

AS: area samples; A: removing old insulation; B: preparing asbestos mixtures for insulation; $\mathrm{C}^{\mathrm{a}}$ : installing insulation using mixtures of powder asbestos and asbestos-containing cord; $\mathrm{C}^{\mathrm{b}}$ : installing insulation using mixtures of powder asbestos; $\mathrm{C}^{\mathrm{c}}$ : installing insulation using asbestos-containing cord; D: disposing of waste from old insulation materials; F: carrying bag with powder asbestos; $N$ : number of samples; PCM: phase contrast microscopy; PCME: phase contrast microscopy equivalent; PS: personal samples.

*PCME concentration is calculated based on the average percentage of asbestos fibers.

** Less than LOD.

aa Standard deviation is shown in parentheses. 
carrying of asbestos bags generated the lowest fiber exposure (one sample) of $0.73 \mathrm{f} / \mathrm{cm}^{3}$. Asbestos exposures across the four TPPs were similar, suggesting that other power plants in Mongolia may have similar levels of asbestos exposure.

\section{Discussion}

In this paper, we document pervasive asbestos overexposure among TPP insulation workers. Our results suggest that insulation worker exposures to asbestos in Mongolia are slightly lower than historical estimates of insulation exposures in the US. Williams et al. estimated that occupational exposure to asbestos among insulation workers in nonshipyard settings ranged from 2 to $10 \mathrm{f} / \mathrm{cm}^{3}$ in the 1970s. ${ }^{22}$ However, if the short-term samples are representative of full-shift exposures, which is likely to be the case given the job duties, then the present level of workers' exposure exceeds current US exposure standards by a factor of 10 . We are concerned that non-insulation workers in power plants may be overexposed to asbestos simply by being in the vicinity of insulation work. Furthermore, with no standards in place for clean-up, showering, or changes of clothing, asbestos exposure outside of the power plants is also likely.

The principal asbestos type found in this study is chrysotile. While there is some controversy about the relative potency of chrysotile versus the amphibole varieties, chrysotile asbestos is considered to be a Group I human carcinogen by the IARC and other agencies. ${ }^{14-16,18,23-25}$

The results of this study indicate that Mongolian insulation workers at TPPs are at an elevated risk of asbestos-related disease. In an accompanying paper, we have for the first time reported a case of mesothelioma arising in a long-term worker in a Mongolian power plant. According to a US Environmental Protection Agency (EPA) estimate, more than 3000 cases of asbestos-related disease mortality per 100000 of the working population are to be expected following 45 years of exposure to asbestos at $1.0 \mathrm{f} / \mathrm{cm}^{3}{ }^{26}$ These results suggest that immediate efforts to reduce exposure, with the goal of eventual total elimination, together with medical surveillance programs, are a high priority for insulation workers and others exposed to asbestos in Mongolia. Medical surveillance measures, such as x-ray assessments, to document additional disease would assist in education initiatives aimed at achieving a total ban.

\section{Limitations of the Study}

The study has several limitations. We collected a relatively small number of samples over a short period (12-81 minutes) to avoid overloading the filter with non-asbestos particles released by thermal insulation work at the workplace. Due to limited funding, a partial-period sample for a full shift was not collected. From the workplace observations and interviews with power plant workers, it was assumed that insulation work was carried out for an entire work shift. Therefore, we considered that collected short-term samples could be used to obtain an indicative estimate of full-shift time-weighted average exposures. The primary purpose of the study was focused on asbestos exposure in the workplace as a baseline for a further investigation of the health exposure of insulation workers if airborne asbestos concentrations are higher than occupational exposure limits. As a result, data on the age, sex, and smoking habits of study subjects were not collected. An in-depth study that collects data on personal and

Table 3 Results of TEM analysis for air samples collected from thermal insulation workplaces in the four Mongolian power plants

\begin{tabular}{|c|c|c|c|c|c|c|}
\hline $\begin{array}{l}\text { Power } \\
\text { plants }\end{array}$ & Job task & $N$ & $\begin{array}{l}\text { Average TEM } \\
\text { concentration, fiber } / \mathrm{cm}^{3} \text { aa }\end{array}$ & $\begin{array}{l}\text { Asbestos concentration, } \\
\text { fiber } / \mathrm{cm}^{3} \text { aa }\end{array}$ & $\begin{array}{l}\text { Fraction of asbestos } \\
\text { fibers }^{\text {aa }}\end{array}$ & $\begin{array}{l}\text { Asbestos } \\
\text { type }\end{array}$ \\
\hline \multirow{5}{*}{$\# 1$} & $C^{c}$ & 1 & 0.78 & 0.78 & 1.00 & $\mathrm{CH}$ \\
\hline & $A$ & 1 & 2.15 & 2.15 & 1.00 & $\mathrm{CH}$ \\
\hline & $\mathrm{F}$ & 1 & 0.59 & 0.53 & 0.91 & $\mathrm{CH}$ \\
\hline & AS & 1 & 0.93 & 0.93 & 1.00 & $\mathrm{CH}$ \\
\hline & Average & 4 & $1.11(0.70)$ & $1.09(0.71)$ & $0.97(0.04)$ & \\
\hline \multirow[t]{6}{*}{$\# 2$} & A & 1 & 0.05 & 0.05 & 0.98 & $\mathrm{CH}$ \\
\hline & D & 2 & $1.46^{*}$ & $1.30^{*}$ & $0.91^{*}$ & $\mathrm{CH}$ \\
\hline & $C^{b}$ & 1 & 0.93 & 0.90 & 0.97 & $\mathrm{CH}, \mathrm{TR}$ \\
\hline & $\mathrm{B}$ & 1 & 1.11 & 1.05 & 0.95 & $\mathrm{CH}, \mathrm{TR}$ \\
\hline & AS & 1 & 0.28 & 0.28 & 1.00 & $\mathrm{CH}$ \\
\hline & Average & 6 & $0.88(0.65)$ & $0.81(0.57)$ & $0.95(0.05)$ & \\
\hline \#3 & $B, C^{b}$ & 2 & $1.73^{*}$ & $1.73^{*}$ & $1.00^{*}$ & $\mathrm{CH}$ \\
\hline$\# 4$ & A & 1 & 0.77 & 0.73 & 0.95 & $\mathrm{CH}$ \\
\hline Average & & 13 & $1.07(0.64)$ & $1.03(0.61)$ & $0.97(0.04)$ & \\
\hline
\end{tabular}

A: removing old insulation; AS: area samples; B: preparing asbestos mixtures for insulation; $\mathrm{C}^{\mathrm{a}}$ : installing insulation using mixtures of powder asbestos and asbestos-containing cord; $C^{b}$ : installing insulation using mixtures of powder asbestos; $C^{c}$ : installing insulation using asbestos-containing cord; $\mathrm{CH}$ : chrysotile; D: disposing of waste from old insulation materials; F: carrying bag with powder asbestos; N: number of samples; TEM: transmission electron microscopy; TR: tremolite.

*Average of two samples.

${ }^{\text {aa }}$ Standard deviation is shown in parentheses. 
workplace exposures to asbestos is now being designed, based on this initial study.

\section{Conclusion}

This paper presents evidence that power plant insulation workers in Mongolia are exposed to elevated airborne concentrations of chrysotile asbestos. There is an immediate and urgent need for the Mongolian government to develop a comprehensive action plan and road map for the elimination of asbestos exposure. The ultimate goal of the action plan should be a total ban on the use of asbestos, as has already been implemented in over 50 countries. In the meantime, employers need to implement and enforce internationally accepted occupational hygiene practices, including engineering and administrative controls shown to reduce exposures in many other countries. Without enforcement, regulations often do not properly protect workers and work-related disease and deaths will still result.

\section{Disclaimer Statements}

Contributors ND, PB, ES, and AF designed the study. ND and PB analyzed the data and wrote the first draft of the manuscript. Ellen Silbergeld participated in the study design and obtained funding. OL and ND collected and interpreted data. All authors contributed to manuscript version and critically revised it.

Funding The Fogarty International Center project "Environmental Risk Factors for Cardiovascular Diseases in Mongolia."

Conflicts of interest None of the authors have conflict of interest in this paper.

Ethics approval The study was approved by the Ethical Committee of Health Sciences University of Mongolia.Please supply the information for 'Disclaimer statements'.

\section{Acknowledgements}

We would like to acknowledge the Fogarty International Center project "Environmental Risk Factors for Cardiovascular Diseases in Mongolia", for funding this study.

\section{References}

1 Mlynarek SP, Van Orden DR. Assessment of potential asbestos exposures from jet engine overhaul work. Regul Toxicol Pharmacol. 2012;63:78-83.

2 Blake CL, Harbison SC, Johnson GT, Harbison RD. Airborne asbestos exposure associated with work on asbestos fire sleeve materials. Regul Toxicol Pharmacol. 2011;61:236-42.

3 Burdett G, Bard D. Exposure of UK industrial plumbers to asbestos, Part I: Monitoring of exposure using personal passive samplers. Ann Occup Hyg. 2007;51(2):121-30.

4 Murbach DM, Madl AK, Unice KM, Knutsen JS, Chapman PS, Brown JL, et al. Airborne concentrations of asbestos onboard maritime shipping vessels (1978-1992). Ann Occup Hyg. 2008;52(4):267-79.

5 Selikoff IJ, Seidman H. Asbestos associated deaths among insulation workers in the United States and Canada, 19671987. Ann N Y Acad Sci. 1991;31(643):1-14.

6 Kangur M. Occupational exposure to asbestos during renovation of oil-shale fueled power plants in Estonia. Int J Occup Saf Ergon. 2007;13(3):341-6.

7 Bhagia LJ, Vyas JB, Shaikh MI, Dodia SL. Chrysotile asbestos exposure in the manufacturing of thermal insulating boards. Environ Monit Assess. 2010;167:559-64.

8 Cely-García MF, Torres-Duque CA, Durán M, Parada P, Sarmiento OL, Breysse PN, et al. Personal exposures to asbestos and respiratory health of heavy vehicle brake mechanics. J Expo Sci Env Epid. 2014;25:26-36.

9 Cely-García MF, Sánchez M, Breysse PN, Ramos-Bonilla JP. Personal exposure to asbestos fibers during brake maintenance of passenger vehicles. Ann Occup Hyg. 2012;56(9):985-99.

10 Felten MK, Knoll L, Eisenhawer C, Ackermann D, Khatab K, Hüdepohl $\mathrm{J}$, et al. Retrospective exposure assessment to airborne asbestos among power industry. J Occup Med Toxicol. 2010;5:15.

11 Khang D. Report on the status of asbestos in Asian Countries. Geneva: World Health Organization; 2012.

12 WHO. A research report on asbestos usage in Mongolia. Research report. Ulaanbaatar: World Health Organization; 2010.

13 Hammond EC, Selikoff IJ, Seidman H. Asbestos exposure, cigarette smoking and death rates. Ann N Y Acad Sci. 1979;330:473-90.

14 USOSHA [Internet]. Safety and health topics, asbestos; 2014 [cited 2014 July 26]. Available from: https:/www.osha.gov/ SLTC/asbestos/.

15 Collegium Ramazzini [Internet]. Statement, asbestos is still with us: repeat call for a universal ban; 2010 [cited 2014 August 26]. Available from: http://www.collegiumramazzini.org/download/ 15_FifteenthCRStatement(2010).pdf.

16 Deng Q, Wang X, Wang M, Lan Y. Exposure - response relationship between chrysotile exposure and mortality from lung cancer and asbestosis. Occup Environ Med. 2012;69(2):816.

17 Al-Delaimy WK. The JPC-SE position statement on asbestos: a long-overdue appeal by epidemiologists to ban asbestos worldwide and end related global environmental injustice. Environ Health Perspect. 2013;121(5):a144-5.

18 Aguilar Madrid G, Beaudry M, Bell W, Bowes D, Brophy J, Burdorf A, et al. Statement in response to asbestos industry efforts to prevent a ban on asbestos in Pakistan: Chrysotile asbestos use is not safe and must be banned. Arch Environ Occup Health. 2013;68(4):243-9.

19 USNIOSH [Internet]. Manual of analytical method 7400, asbestos and other fibers by PCM, Revision 2; 1996 [cited 2014 April 14]. Available from: http://www.cdc.gov/niosh/docs/ 2003-154/pdfs/7400.pdf.

20 USNIOSH [Internet]. Manual of analytical method 7402, asbestos by TEM, Revision 2; 1994 [cited 2014 April 14]. Available from: http://www.cdc.gov/niosh/docs/2003-154/pdfs/ 7402.pdf.

21 USOSHA [Internet]. Occupational safety and health standard, asbestos; 2012 [cited 2014 April 14]. Available from: https:// www.osha.gov/pls/oshaweb/owadisp.show_document?p_table $=\mathrm{S}$ TANDARDS\&p_id $=9995$

22 Williams PR, Phelka AD, Paustenbach DJ. A review of historical exposures to asbestos among skilled craftsmen (1940-2006). J Toxicol Env Health. 1996;10(5):319-77.

23 International Agency for Research on Cancer. Monographs: arsenic, metals, fibers and dust, vol 100C, review of human carcinogens. Lyon: WHO; 2012.

24 Stayner LT, Dankovic DA, Lemen RA. Asbestos and cancer risk: a review of the amphibole hypothesis. Am J Public Health. 1996;86(2):179-86.

25 American Conference of Governmental Industrial Hygienists $\left(\mathrm{ACGIH}^{*}\right)$. Thershold Limit Values for Chemical Substances in the Work Environment. In $2014 \mathrm{TLV}^{*}$ s and BEI*s Cincinnati, Ohio. ACGIH, 2014

26 USEPA. Airborne Asbestos Health Assessment Update; 1986. Report No.: EPA/600/8-84/003. 